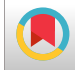

\title{
Prevalence of Escherichia coli and Klebsiella pneumoniae, Producing Extended-Spectrum Beta-Lactamase (ESBLs) from Clinical Specimen in
} Khuzestan, Iran

\author{
Sahar Besharati Zadeh ${ }^{1}$, Pegah Shakib ${ }^{2}$, Mohammad Reza Zolfaghari ${ }^{1{ }^{*}}$ and Ahmad Farajzadeh \\ Sheikh ${ }^{3, * *}$ \\ ${ }^{1}$ Department of Microbiology, Qom Branch, Islamic Azad University, Qom, Iran \\ ${ }^{2}$ Razi Herbal Medicines Research Center, Lorestan University of Medical Sciences, Khorramabad, Iran \\ ${ }^{3}$ Department of Microbiology, School of Medicine, Ahvaz Jundishapur University of Medical Sciences, Ahvaz, Iran \\ "Corresponding author: Department of Microbiology, Qom Branch, Islamic Azad University, Qom, Iran. Email: mreza.zolfaghary@gmail.com \\ "Corresponding author: Department of Microbiology, School of Medicine, Ahvaz Jundishapur University of Medical Sciences, Ahvaz, Iran. Email: farajzadeh12@yahoo.com \\ Received 2021 January 06; Revised 2021 January 26; Accepted 2021 February 06.
}

\begin{abstract}
Background: A major problem in the treatment of the infectious diseases healthcare centers is extended-spectrum beta-lactamase (ESBL)-producing bacteria.

Objectives: The aim of present study was to identify the antibiotic sensitivity pattern and prevalence of the $b l a C T X, b l a_{T E M}$, and $b l a_{S H V}$ genes in Escherichia coli and Klebsiella pneumoniae strains.

Methods: In this study, E. coli and K. pneumoniae specimens were collected in Shushtar hospitals, Khuzestan (southwest Iran), from March to October 2015. Sensitivity antibiotic pattern performed by disc diffusion method. Double disc synergy test (DDST) done for identifying ESBLs isolates and PCR for bla $_{\text {TEM }}$, bla $_{S H V}$, and bla $a_{\text {CTX-M }}$ genes.

Results: One hundred E. coli and $30 \mathrm{~K}$. pneumoniae isolates were collected from different specimens. The highest rates of antibiotic resistance related to cefotaxime and aztreonam in E. coli and K. pneumoniae. ESBL-harboring K. pneumoniae and E. coli were 13.5 and $28 \%$, respectively. Overall, bla TEM was the most prevalent ESBL gene.

Conclusions: In this study, the rate of antibiotic resistance was high, and due to the carrying of coding genes on mobile genetic elements and the ability of these elements to carry genes that create resistance to other antibiotic families, identification and isolation of these isolates are essential to find effective antibiotics and eliminate the infection.
\end{abstract}

Keywords: Escherichia coli, Klebsiella pneumonia, Extended-Spectrum Beta-Lactamase (ESBL), Double-Disc Synergy Test (DDST)

\section{Background}

Escherichia coli (E. coli) and Klebsiella pneumoniae (K. pneumoniae) are opportunistic Gram-negative bacilli of the Enterobacteriaceae family and cause nosocomial infections. K. pneumoniae causes pneumonia, sepsis, and urinary tract infections, and E. coli is an indicator of urinary tract infection and causes pneumonia, sepsis, and bacteremia $(1,2)$.

Bacteria are immune to the harmful effects of antibiotics using a variety of mechanisms, one of which is the production of broad-spectrum beta-lactamases (ESBL) enzymes (3). Today, the prevalence of broad-spectrum betalactamase-producing bacteria is increasing and has raised concerns in treatment systems because they increase treatment costs, increase treatment duration, and increase mortality in patients (4). According to the results of studies, Gram-negative bacteria of E. coli and K. pneumoniae have the highest resistance, and mainly these strains carry ESBLs $(5,6)$. ESBLs are divided into 4 classes (A, B, C, D), which are mainly inhibited by inhibitors such as clavulanic acid, tazobactam, and sulbactam (7). According to this classification, the enzymes SHV, TEM, and CTX-M are in class A (8). More than 150 ESBLs have been reported so far. Broad-spectrum beta-lactamases are broad-spectrum hydrolyzing enzymes of cephalosporins (9). ESBLs are located on the plasmid, so they are easily transferable between different strains. The most common ESBLs are derived from TEM and SHV (10). Beta-lactamase TEM-1 is the most common beta-lactamase in Gram-negative bacilli Enterobacteriaceae family. Different types of beta-lactamase TEM have been formed by substituting amino acids for the active site of the TEM-1 enzyme, based on which about 130 betalactamase TEM has been identified. SHV beta-lactamase 
was first discovered by Pitton in 1972, which is a class A betalactamase. In the last two decades, widespread prevalence of CTX-M beta-lactamases has been reported in various regions (11-13). The first reports of CTX-M were recorded in the early 1990s. Unlike TEM and SHV, CTX-M beta-lactamases have a more destructive effect against cefotaxime and ceftriaxone than ceftazidime. CTX-M beta-lactamases are divided into five main groups based on amino acid changes, including CTX-M-1, CTX-M-2, CTX-M-8, CTX-M-9, and CTX-M25 (10).

Therefore, considering the transfer of resistance genes by ESBL isolates and the identification of ESBL-producing isolates, it is very important to isolate these isolates to prevent treatment failure $(14,15)$. A simple and inexpensive phenotypic technique for isolating these isolates is the double-disc synergy test (DDST), which can be performed in many laboratories (14).

\section{Objectives}

The aim of the present study was to detect ESBLsproducing E.coli and K. pneumoniaee strains isolated from clinical specimens.

\section{Methods}

In this cross-sectional study, E. coli and K. pneumoniae strains were isolated in Shushtar hospitals, Khuzestan province (southwest Iran), from urine, blood, wound, and sputum specimens from March to October 2015. After culturing on Macconkey and Blood agar (Merck, Germany), colonies were identified by biochemical and microbiological test, including gram stain, oxidase, catalase, indol, motility, citrate, and TSI Urea, and lysine decarboxylase (16). The isolated bacteria were kept at $-20^{\circ} \mathrm{C}$ in tryptic soy broth (TBS) plus 20\% Glycerol.

\subsection{Antimicrobial Sensitivity Pattern}

The antibiotic sensitivity pattern was performed according to the Clinical and Laboratory Standards Institute (CLSI) guidelines by disc diffusion test. In this method, ceftazidime (30 $\mu \mathrm{g})$, ceftriaxone (30 $\mu \mathrm{g})$, cefotaxime (30 $\mu \mathrm{g})$, aztreonam (30 $\mu \mathrm{g})$, gentamicin $(10 \mu \mathrm{g})$, ciprofloxacin (5 $\mu \mathrm{g})$, amikacin $(30 \mu \mathrm{g})$ (MAST, Germany) discs were used on Mueller- Hinton agar (MHA) (17).

\subsection{ESBLs Phenotypic Screening}

Double-disc synergy test (DDST) carrying out for isolation of ESBL-producing strains. In this test, ceftazidime (30 $\mu \mathrm{g})$, cefotaxime (30 $\mu \mathrm{g})$, ceftazidime + clavulanic acid $(30 / 10 \mu \mathrm{g})$, and cefotaxime + clavulanic acid $(30 / 10 \mu \mathrm{g})$ were used on Mueller-Hinton agar. After incubation at $37^{\circ} \mathrm{C}$ for 18 hours, if the inhibition zone around the combination and single disc was $\geq 5 \mathrm{~mm}$, the strain was considered ESBL positive. The positive and negative control isolates used in this test were K. pneumoniae ATCC 700603 and E. coli ATCC 25922, respectively (1).

\subsection{Detection of bla ${ }_{\mathrm{TEM}}$, bla ${ }_{S H V}$, and bla ${ }_{\mathrm{CTX}-\mathrm{M}}$ Genes}

Bacterial genomic DAN was extracted from all strains according to the manufacturer's instruction (Sinaclon Co, Iran). Bla $a_{T E M}, b l a_{S H V}$, and bla $a_{C T X-M}$ genes detected by polymerase chain reaction (PCR) assay using specific primers and DNA template (Table 1). Following the amplification, electrophoresis was carried out on $1.5 \%$ agarose gels for 50 min at $90 \mathrm{~V}$ that were visualized using a UV gel documentation system (BioRad, USA).

\subsection{Statistical Analysis}

In this study, the statistical program (Statistical Package for the Social Sciences, SPSS) version 19 was used. Differences between proportions were analyzed using chisquare test, and $\mathrm{P} \leq 0.05$ was considered significant.

\section{Results}

In this study, one hundred E. coli and thirty K. pneumoniae isolates were isolated from different clinical samples. Table 1 shows the demographic characteristics of the strains isolated from clinical specimens. As shown in Table 2, the highest frequency of E. coli and K. pneumoniae was related to the intensive care unit (ICU) and emergency room, and most strains were isolated from urine samples.

The highest rates of antimicrobial resistance among E. coli isolates were obtained for cefotaxime 46 (46\%), followed by ceftazidime 43 (43\%), ceftriaxone 40 (40\%), aztreonam 33 (33\%), gentamicin 32 (32\%), amikacin 25 (25\%), and ciprofloxacin 23 (23\%). On the other hand, the K. pneumoniae strains were resistant to ceftazidime 9 (30\%), ceftriaxone 13 (43.5\%), aztreonam 15 (50\%), gentamicin 9 (30\%), amikacin 13 (43.5\%), and ciprofloxacin 7 (23.5\%).

The overall frequency of ESBL-harboring K. pneumoniae and E. coli were $13.5 \%$ (4/30) and 28 (28/100) by DDST, respectively. According to the PCR assay results, among 28 ESBLsproducing E. coli, bla ${ }_{\text {TEM }}(\mathrm{N}=28,100 \%)$ was the most prevalent ESBL gene, followed by bla ${ }_{\text {CTX-M }}(\mathrm{N}=26,92.8 \%)$, and bla ${ }_{S H V}(\mathrm{~N}=1,3.5 \%)$. Among four ESBL-producing K. pneumoniae isolates, 4 (100\%), 4 (100\%), and 3 (75\%) carried bla ${ }_{\text {CTX-M }}$, bla ${ }_{T E M}$, and bla ${ }_{S H V}$ genes, respectively (Figure 1). 


\begin{tabular}{|c|c|c|c|c|c|}
\hline Target Gene & Primer Sequence $\left(5^{\prime}-3^{\prime}\right)$ & Amplicon Size (bp) & Conditions & Volume Reactions & Reference \\
\hline bla $_{C T X-M}$ & $\begin{array}{l}\text {-TTTGCGATGTGCAGTACCAGTAA-; } \\
\text {-CGATATCGTTGGTGGTGCCATA- }\end{array}$ & 590 & $\begin{array}{c}1 \text { cycle: } 94^{\circ} \mathrm{C} ; 4 \mathrm{~min} ; 35 \text { cycle: } 94^{\circ} \mathrm{C} \\
45 \mathrm{~s} ; 56^{\circ} \mathrm{C} ; 45 \mathrm{~s} ; 72^{\circ} \mathrm{C} ; 45 \mathrm{~s} ; 1 \text { cycle: } \\
72^{\circ} \mathrm{C} ; 7 \text { min }\end{array}$ & $\begin{array}{c}\text { 10X PCR Buffer: } 2.5 \mu \mathrm{L}, 10 \mathrm{mM} \\
\text { dNTPs: } 0.5 \mu \mathrm{L}, 10 \text { mM MgCl } 2: 0.75 \\
\mu \mathrm{L}, 10 \text { pmol F }+ \text { R Primer: } 1.25 \mu \mathrm{L} \text {, } \\
\text { Taq DNA polymerase }(5 \mathrm{u} \mu \mathrm{L}): 0.2 \\
\mu \mathrm{L} \text {, Template DNA: } 5 \mu \mathrm{L} ; \mathrm{H}_{2} \mathrm{O} \text { up } \\
\text { to } 25 \mu \mathrm{L}\end{array}$ & (18) \\
\hline $\boldsymbol{b l a}_{\text {TEM }}$ & $\begin{array}{l}\text {-AGTGCTGCCATAACCATGAGTG-; } \\
\text {-CTGACTCCCC GTCGTGTAGATA- }\end{array}$ & 431 & $\begin{array}{c}1 \text { cycle: } 95^{\circ} \mathrm{C} ; 5 \mathrm{~min} ; 36 \text { cycle: } 95^{\circ} \mathrm{C} \text {; } \\
60 \mathrm{~s} ; 54^{\circ} \mathrm{C} ; 60 \mathrm{~s} ; 72^{\circ} \mathrm{C} ; 60 \mathrm{~s} ; 1 \text { cycle: } \\
72^{\circ} \mathrm{C} ; 5 \text { min }\end{array}$ & $\begin{array}{l}\text { 10X PCR Buffer: } 2.5 \mu \mathrm{L}, 10 \mathrm{mM} \\
\text { dNTPs: } 0.5 \mu \mathrm{l}, 10 \mathrm{mM} \mathrm{MgCl}{ }_{2}: 0.75 \\
\mu \mathrm{L}, 10 \text { pmol F }+ \text { R Primer: } 1.25 \mu \mathrm{L} \text {, } \\
\text { Taq DNA polymerase }(5 \mathrm{u} \mu \mathrm{L}): 0.2 \\
\mu \mathrm{L} \text {, Template DNA: } 5 \mu \mathrm{L} ; \mathrm{H}_{2} \mathrm{O} \text { up } \\
\text { to } 25 \mu \mathrm{L}\end{array}$ & (19) \\
\hline $\boldsymbol{b l a}_{S H V}$ & $\begin{array}{l}\text {-GATGAACGCTTTCCCATGATG-; } \\
\text {-CGCTGTTATCGCTCATGGTAA- }\end{array}$ & 214 & $\begin{array}{c}1 \text { cycle: } 94^{\circ} \mathrm{C} ; 5 \mathrm{~min} ; 38 \text { cycle: } 94^{\circ} \mathrm{C} \text {; } \\
60 \mathrm{~s} ; 53^{\circ} \mathrm{C} ; 60 \mathrm{~s} ; 72^{\circ} \mathrm{C} ; 60 \mathrm{~s} ; 1 \text { cycle: } \\
72^{\circ} \mathrm{C} ; .7 \mathrm{~min}\end{array}$ & $\begin{array}{l}\text { 10X PCR Buffer: } 2.5 \mu \mathrm{L}, 10 \mathrm{mM} \\
\text { dNTPs: } 0.5 \mu \mathrm{L}, 10 \mathrm{mM} \mathrm{MgCl} 2: 0.75 \\
\mu \mathrm{L}, 10 \text { pmol F+ R Primer: } 1.25 \mu \mathrm{L} \text {, } \\
\text { Taq DNA polymerase }(5 \mathrm{u} \mu \mathrm{L}): 0.2 \\
\mu \mathrm{L} \text {, Template DNA: } 5 \mu \mathrm{L} ; \mathrm{H}_{2} \mathrm{O} \text { up } \\
\text { to } 25 \mu \mathrm{L}\end{array}$ & (19) \\
\hline
\end{tabular}

\begin{tabular}{|c|c|c|}
\hline Variables & E. $\operatorname{coli}(\mathrm{N}=100)$ & K. pneumoniae $(\mathrm{N}=30)$ \\
\hline Gender & $76(76)$ & $18(60)$ \\
\hline \multicolumn{3}{|l|}{ Female } \\
\hline Male & $24(24)$ & $12(40)$ \\
\hline Clinical specimen & $84(84)$ & $16(53.47)$ \\
\hline \multicolumn{3}{|l|}{ Urine } \\
\hline Blood & $12(12)$ & $5(16.6)$ \\
\hline Sputum & $1(1)$ & $5(16.6)$ \\
\hline Wound & $3(3)$ & $(13.3)$ \\
\hline Sections & $29(29)$ & $9(30)$ \\
\hline \multicolumn{3}{|l|}{ ICU } \\
\hline Emergency & $38(38)$ & $9(30)$ \\
\hline Surgery & $8(8)$ & $4(13.3)$ \\
\hline Internal & $25(25)$ & $8(26.7)$ \\
\hline
\end{tabular}

${ }^{a}$ Values are expressed as No. (\%).

\section{Discussion}

K. pneumoniae and E. coli are the members of the Enterobacteriaceae family that cause nosocomial infections. Recently, in many parts of the world, antibiotic resistance due to the presence of beta-lactamase enzymes increased against a wide variety of antibiotics (20-22). In this study, the results indicate a high rate of antibiotic resistance, which is consistent with the results of many studies around the world, but in some studies, this rate of resistance is low, which indicates differences in the pattern of antibiotic use in different regions $(23,24)$. On the other hand, the frequency of ESBL strains was high in this investigation.
In Qureshi's study et al. in Pakistan, 98.9, 96.7, and 93.4\% resistance rates were described in E. coli against cefotaxime, ceftazidime, and cefuroxime (25). In Moayednia et al. study in Isfahan, E. coli clinical isolates showed 32, 38, and $33.4 \%$ resistance rate against ceftazidime, cefotaxime, and ciprofloxacin antibiotics (26). Given that the trend of antimicrobial resistance among clinical isolates in any geographical area is essential for recommendations in experimental antibiotic treatment of infections. The aim of this study was to determine the antimicrobial resistance and diagnosis of ESBL among E. coli and K. pneumoniae strains, which are dominant producers of ESBL. During the past decade, ESBL-producing E. coli and K. pneumonia isolates greatly differ worldwide. For example, at University Hos- 
A

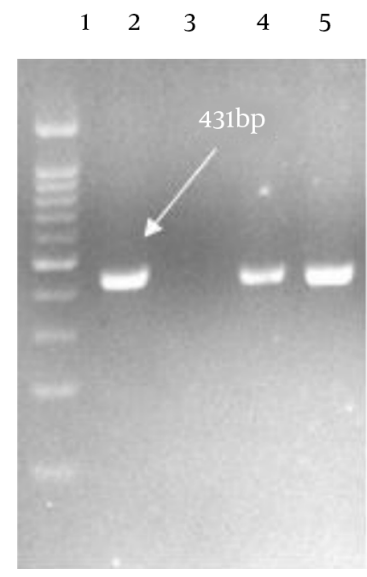

B
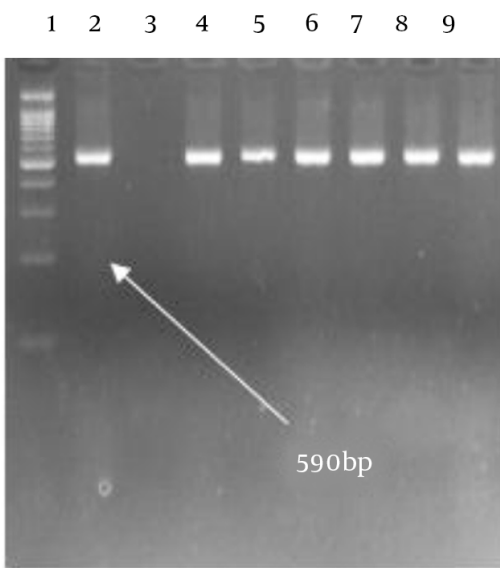

C

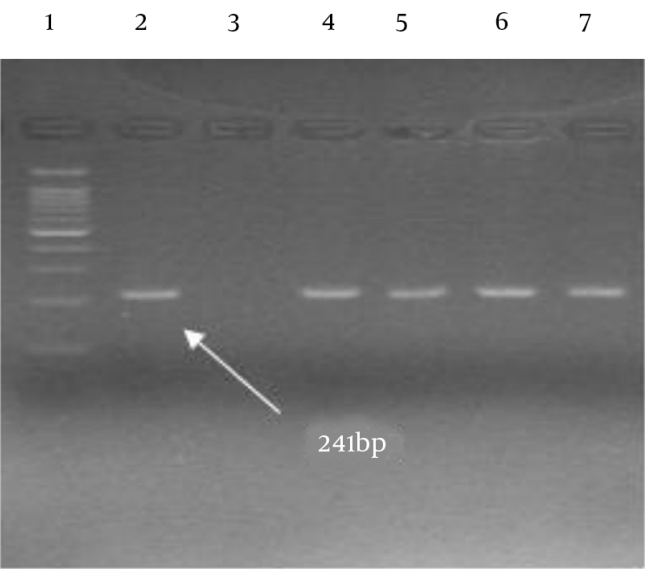

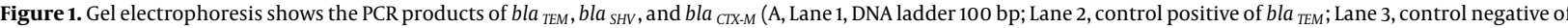
bla TEM ; Lanes 4 and 5, clinical isolates carrying bla ${ }_{T E M}$; B, Lane 1, DNA ladder 100 bp; Lane 2, control positive of bla $a_{C X-M}$; Lane 3, control negative of bla ${ }_{C T X-M}$; Lanes 4 - 9, clinical

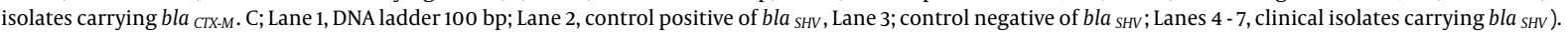

pitals in Aleppo city, Syria, ESBL screened in E. coli and $K$. pneumoniae in abundance 62.89 and $67.5 \%$ (5). On the other hand, our result is higher compared to other reports $26.5 \%$ of E. coli and $43 \%$ of $K$. pneumoniae were ESBL-producing strains from Imam Reza Hospital of Mashhad, Iran (27). The frequency of ESBL-producing E. coli isolates was reported at 69.4\% in Paris (28) and 41.6\% in India (29).

In the current study, genotypic survey showed all isolates were positive for at least one of the studied genes on all phenotypically ESBL-producing E. coli and K. pneumoniae strains. Bla TEM was revealed in all tested isolates; so, bla TEM was the most prevalent gene in E. coli and K.pneumoniae ESBL-positive isolates. These results are in agreement with other studies, such as Wollheim et al., in southern Brazil bla TEM (95.3\%) was the frequent gene followed by the bla ${ }_{C T X-M}(82.8 \%)$, and the bla ${ }_{S H V}$ gene (42.2\%) among K. pneumoniae and 66.7, 50,11.1\% of ESBL-producing E. coli carrying bla ${ }_{T E M}$, bla ${ }_{\text {CTX-M }}$, and bla ${ }_{S H V}$ gene, respectively (2). However, in AL-Subol study bla ${ }_{C T X-M}$ was the commonest genotype $(100 \%$ of $K$. pneumoniae and $76.14 \%$ of $E$. coli isolates), and followed by bla ${ }_{S H V}$ was identified in $K$. pneumoniae (92.59\%) and E. coli (57.95\%) isolates (5). Peter Montso et al. in North-West Province South Africa detected bla $_{\text {TEM }}$, bla ${ }_{S H V}$, and bla ${ }_{\text {CTX-M }}$ genes in E. coli isolates (85.5, 69.6 , and 58\%, respectively) (30). Gautam study in India reported bla ${ }_{\text {TEM }}$ gene was the most prevalent ESBL in E. coli and $K$. pneumoniae strains (31).

According to the results of this study, a high percentage of E. coli and K. pneumoniae isolated from Shushtar hospital patients produced ESBL and TEM genes. This indicates the need for changing the strategy of antibiotic therapy use to prevent transmission.

The difference in the prevalence of these genes in different studies may be due to differences in the pattern of use of antibiotics, including cephalosporins. Excessive use of antibiotics causes the spread of antibiotic resistance genes among bacteria, which can be prevented by changing the strategy of using antibiotics to transfer these genes among bacteria.

\subsection{Conclusion}

Because the bla ${ }_{T E M}, b_{\text {SHV }}$, and bla ${ }_{\text {CTX-M }}$ genes are carried by plasmids, and these plasmids can carry other antibiotic resistance genes. They make it difficult to treat infections caused by antibiotic-resistant strains. Therefore, identification of ESBL-producing isolates can be effective in the treatment of these infections.

\section{Acknowledgments}

The authors would like to thank laboratory experts of Bagiatola Hospital in Shoshtar, Khuzestan province, Iran.

\section{Footnotes}

Authors' Contribution: Study concept and design, Ahmad Farajzadeh Sheikh; Acquisition of data, Sahar Besharati Zadeh; Analysis and interpretation of data, Mohammad Reza Zolfaghari; Drafting of the manuscript, Pegah Shakib; Critical revision of the manuscript for important intellectual content, Mohammad Reza Zolfaghari; Sta- 
tistical analysis, Ahmad Farajzadeh Sheikh; Administrative, technical, and material support, Ahmad Farajzadeh Sheikh; Study supervision, Mohammad Reza Zolfaghari.

Conflict of Interests: There were no conflicts of interest. Ethical Approval: The study was approved by the Islamic Azad University, Qom Branch, Qom, Iran.

Funding/Support: There was no funding/support.

\section{References}

1. Alqasim A, Abu Jaffal A, Alyousef AA. Prevalence of multidrug resistance and extended-spectrum $\beta$-lactamase carriage of clinical uropathogenic Escherichia coli Isolates in Riyadh, Saudi Arabia. Int J Microbiol. 2018;2018:3026851. doi: 10.1155/2018/3026851. [PubMed: 30305814]. [PubMed Central: PMC6165594].

2. Wollheim C, Guerra IM, Conte VD, Hoffman SP, Schreiner FJ, Delamare AP, et al. Nosocomial and community infections due to class A extended-spectrum $\beta$-lactamase (ESBLA)-producing Escherichia coli and Klebsiella spp. in southern Brazil. Braz J Infect Dis. 2011;15(2):13843. [PubMed: 21503400].

3. Manoharan A, Premalatha K, Chatterjee S, Mathai D, Sari Study Group. Correlation of TEM, SHV and CTX-M extended-spectrum beta lactamases among Enterobacteriaceae with their in vitro antimicrobial susceptibility. Indian J Med Microbiol. 2011;29(2):161-4. doi: 10.4103/0255-0857.81799. [PubMed: 21654112].

4. Polse RF, Yousif SY, Assafi MS. Prevalence and molecular characterization of extended spectrum beta-Lactamases-producing uropathogenic Escherichia coli isolated in Zakho, Iraq. J Microbiol Infect Dis. 2016;6(4):163-7. doi: 10.5799/jmid.328863.

5. Al-Subol I, Youssef N. Prevalence of CTX-M, TEM and SHV betalactamases in clinical isolates of Escherichia coli and Klebsiella pneumoniae isolated from Aleppo University Hospitals, Aleppo, Syria. Arch Clin Infect Dis. 2015;10(2). e22540. doi: 10.5812/archcid.22540.

6. Moosavian M, Deiham B. Distribution of TEM, SHV and CTX-M genes among ESBL-producing Enterobacteriaceae isolates in Iran. Afr J Microbiol Res. 2012;6(26):5433-9. doi: 10.5897/ajmr11.017.

7. Bourjilat F, Bouchrif B, Dersi N, Claude JD, Amarouch H, Timinouni $M$. Emergence of extended-spectrum beta-lactamases-producing Escherichia coli in community-acquired urinary infections in Casablanca, Morocco. J Infect Dev Ctries. 2011;5(12):850-5. doi: 10.3855/jidc.1490. [PubMed: 22169783].

8. Bush K. Characterization of beta-lactamases. Antimicrob Agents Chemother. 1989;33(3):259-63. doi: 10.1128/aac.33.3.259. [PubMed: 2658779]. [PubMed Central: PMC171476].

9. Rupp ME, Fey PD. Extended spectrum beta-lactamase (ESBL)producing Enterobacteriaceae: considerations for diagnosis, prevention and drug treatment. Drugs. 2003;63(4):353-65. doi: 10.2165/00003495-200363040-00002. [PubMed: 12558458].

10. Tzouvelekis LS, Tzelepi E, Tassios PT, Legakis NJ. CTX-M-type betalactamases: An emerging group of extended-spectrum enzymes. Int $J$ Antimicrob Agents. 2000;14(2):137-42. doi: 10.1016/s09248579(99)00165-x. [PubMed: 10720804].

11. Soria Segarra C, Soria Baquero E, Cartelle Gestal M. High prevalence of CTX-M-1-like enzymes in urinary isolates of Escherichia coli in Guayaquil, Ecuador. Microb Drug Resist. 2018;24(4):393-402. doi: 10.1089/mdr.2017.0325. [PubMed: 29298110].

12. Afema JA, Ahmed S, Besser TE, Jones LP, Sischo WM, Davis MA. Molecular epidemiology of dairy cattle-associated Escherichia coli carrying blaCTX-M genes in Washington State. Appl Environ Microbiol. 2018;84(6). doi: 10.1128/AEM.02430-17. [PubMed: 29305512]. [PubMed Central: PMC5835732].

13. Niumsup PR, Tansawai U, Na-Udom A, Jantapalaboon D, Assawatheptawee K, Kiddee A, et al. Prevalence and risk factors for intestinal car- riage of CTX-M-type ESBLs in Enterobacteriaceae from a Thai community. EurJClin Microbiol Infect Dis. 2018;37(1):69-75. doi:10.1007/s10096017-3102-9. [PubMed: 28918585].

14. Sturenburg E, Mack D. Extended-spectrum beta-lactamases: Implications for the clinical microbiology laboratory, therapy, and infection control. J Infect. 2003;47(4):273-95. doi: 10.1016/s0163-4453(03)000963. [PubMed: 14556752].

15. Sturenburg E, Sobottka I, Noor D, Laufs R, Mack D. Evaluation of a new cefepime-clavulanate ESBL Etest to detect extended-spectrum beta-lactamases in an Enterobacteriaceae strain collection. J Antimicrob Chemother. 2004;54(1):134-8. doi: 10.1093/jac/dkh274. [PubMed: 15150168].

16. Forbes BA, Sahm DF, Weissfeld AS. Diagnostic microbiology. Missouri, USA: Mosby St Louis; 2007.

17. Cockerill F; Clinical Laboratory Standards Institute. Methods for dilution antimicrobial susceptibility tests for bacteria that grow aerobically: Approved standard. Pennsylvania, USA: Clinical and Laboratory Standards Institute; 2012.

18. Edelstein M, Pimkin M, Palagin I, Edelstein I, Stratchounski L. Prevalence and molecular epidemiology of CTX-M extendedspectrum beta-lactamase-producing Escherichia coli and Klebsiella pneumoniae in Russian hospitals. Antimicrob Agents Chemother. 2003;47(12):3724-32. doi: 10.1128/aac.47.12.3724-3732.2003. [PubMed: 14638473]. [PubMed Central: PMC296190].

19. Junyoung K, Semi J, Hogeun R, Bokkwon L, Misun P, Hoanjong L, et al. Rapid detection of extended spectrum $\beta$-lactamase (ESBL) for Enterobacteriaceae by use of a multiplex PCR-based method. Infect Chemother. 2009;41(3):181-4. doi: 10.3947/ic.2009.41.3.181.

20. Bajpai T, Pandey M, Varma M, Bhatambare GS. Prevalence of TEM, SHV, and CTX-M beta-lactamase genes in the urinary isolates of a tertiary care hospital. Avicenna J Med. 2017;7(1):12-6. doi: 10.4103/22310770.197508. [PubMed: 28182026]. [PubMed Central: PMC5255976].

21. Koudokpon H, Dougnon V, Hadjadj L, Kissira I, Fanou B, Loko F, et al. First sequence analysis of genes mediating extended-spectrum beta-lactamase (ESBL) bla-TEM, SHV-and CTX-M production in isolates of Enterobacteriaceae in Southern Benin. Infect Chemother. 2018;In Press(In Press). doi: 10.5812/iji.83194.

22. Sanjit Singh A, Lekshmi M, Prakasan S, Nayak BB, Kumar S. Multiple antibiotic-resistant, extended spectrum-beta-lactamase (ESBL)producing Enterobacteria in fresh seafood. Microorganisms. 2017;5(3). doi: 10.3390/microorganisms5030053. [PubMed: 28867789]. [PubMed Central: PMC5620644].

23. Song W, Lee KM, Kim HS, Kim JS, Kim J, Jeong SH, et al. Clonal spread of both oxyimino-cephalosporin- and cefoxitin-resistant Klebsiella pneumoniae isolates co-producing SHV-2a and DHA-1 beta-lactamase at a burns intensive care unit. Int J Antimicrob Agents. 2006;28(6):5204. doi: 10.1016/j.ijantimicag.2006.07.019. [PubMed: 17095195].

24. Moland ES, Hong SG, Thomson KS, Larone DH, Hanson ND. Klebsiella pneumoniae isolate producing at least eight different beta-lactamases, including AmpC and KPC beta-lactamases. Antimicrob Agents Chemother. 2007;51(2):800-1. doi: 10.1128/AAC.01143-06. [PubMed: 17145795]. [PubMed Central: PMC1797768].

25. Qureshi $\mathrm{M}$, Asif N, Baig S. Evaluation of extended spectrum $\beta$ lactamase mediated resistance in Escherichia coli and Klebsiella in urinary tract infection at a tertiary care hospital. Biomedica. 2013;29(2):78-81.

26. Moayednia R, Shokri D, Mobasherizadeh S, Baradaran A, Fatemi SM, Merrikhi A. Frequency assessment of $\beta$-lactamase enzymes in Escherichia coli and Klebsiella isolates in patients with urinary tract infection. J Res Med Sci. 2014;19(Suppl 1):S41-5. [PubMed: 25002893]. [PubMed Central: PMC4078376].

27. Ashrafian F, Askari E, Kalamatizade E, Ghabouli-Shahroodi MJ, NaderiNasab M. The frequency of extended spectrum beta lactamase (ESBL) in Escherichia coli and Klebsiella pneumoniae: A Report from Mashhad, Iran. J Med Bacteriol. 2013;2(1-2):12-9. 
28. Chervet D, Lortholary O, Zahar JR, Dufougeray A, Pilmis B, Partouche $\mathrm{H}$. Antimicrobial resistance in community-acquired urinary tract infections in Paris in 2015. Med Mal Infect. 2018;48(3):188-92. doi: 10.1016/j.medmal.2017.09.013. [PubMed: 29054298].

29. Bajpai T, Pandey M, Varma M, Bhatambare GS. Prevalence of extended spectrum beta-lactamase producing uropathogens and their antibiotic resistance profile in patients visiting a tertiary care hospital in central India: Implications on empiric therapy. Indian J Pathol Microbiol. 2014;57(3):407-12. doi: 10.4103/0377-4929.138733. [PubMed: 25118732].

30. Montso KP, Dlamini SB, Kumar A, Ateba CN. Antimicrobial resis- tance factors of extended-spectrum beta-lactamases producing Escherichia coli and Klebsiella pneumoniae isolated from cattle farms and raw beef in North-West Province, South Africa. Biomed Res Int 2019;2019:4318306. doi: 10.1155/2019/4318306. [PubMed: 31915693]. [PubMed Central: PMC6935440].

31. Gautam V, Thakur A, Sharma M, Singh A, Bansal S, Sharma A, et al. Molecular characterization of extended-spectrum beta-lactamases among clinical isolates of Escherichia coli \& Klebsiella pneumoniae: A multi-centric study from tertiary care hospitals in India. Indian J Med Res. 2019;149(2):208-15. doi: 10.4103/ijmr.IJMR_172_18. [PubMed: 31219085]. [PubMed Central: PMC6563744]. 